\title{
miscellany
}

\section{Board of International Affairs Senior Volunteer Programme}

Since its conception in September 2001, the Board of International Affairs has been considering the possibility of setting up a framework that would enable consultant psychiatrists to offer their expertise to low-income countries in a structured way.

Many low- and middle-income countries are known to suffer either from an acute shortage of psychiatrists (the UK has around one psychiatrist per 1525,000 population whereas the ratio in sub-Saharan Africa is less than one psychiatrist per million population and India has around four psychiatrists per million) or a skills gap (e.g. Eastern Europe experiences an historic isolation from the rest of the international community and knowledge base), with consequences for both specialist and primary care mental health services in those countries.

The College has many practising and recently retired consultant psychiatrists, some of whom would be prepared to offer their time to support other countries. However, recipient countries do not have ready access to the details of psychiatrists who would be prepared to help and psychiatrists do not have ready access to details of countries where their help might be valued. Therefore it was felt that the College should endeavour to play a key role in facilitating contacts between countries and psychiatrists willing to offer support.

We are delighted to announce that the long-awaited database, which will allow the College to store and exchange relevant information between volunteers and host organisations, is now live. On receipt of an application from a host country/ institution, this database will enable us to swiftly identify a suitable volunteer whose skills, availability, language competence, etc. match the requirements specified by the host.

We are aware that one of the main obstacles in this initiative is the issue of funding. We are hopeful that the College will provide the infrastructure for the administrative side of the programme but it will not be able to offer any financial assistance to volunteers. Fundraising activities are not feasible either as the College has limited resources in terms of staff availability. We believe that, initially, volunteers will be willing to fund their own travel, with the host institution sometimes able to contribute (e.g. basic accommodation, meals, local transport, etc.)

To date, the College has received over 120 'expressions of interest' and over 40 completed volunteer questionnaires.

If you require any further information about the programme, or would like a volunteer/host questionnaire, please contact the International Affairs Unit (e-mail: jcarroll@rcpsych.ac.uk).

\section{forthcoming events}

The Royal College of Psychiatrists Transcultural Special Interest Group would like to announce the following conference: Global to Local: The Psychopathology and Management of Conflict and Disaster. The event will take place in the Council Room at the Royal College of Psychiatrists, London on Tuesday 25 October 2005 from 10.00 to 16.00 h. Cost: $£ 50$ working, $£ 25$ retired. Please contact Dr Kwame McKenzie for an application form (e-mail:

k.mckenzie@medsch.ucl.ac.uk)

The Department of Psychotherapy, Milton Keynes Primary Care Trust would like to announce a Seminar on Dreams to be held on Friday 4 November 2005. Psychologist Joe Griffin, a graduate of the London School of Economics, spent 12 years researching the nature and function of dreaming. He will present his findings in a coherent theory that explains the biological basis of dreaming, including the REM state and the psychological need to dream. His theory of dreams as 'eliminating unfulfilled expectations' provides a more rational explanation than older dream theories. A significant proportion of the 6-hour seminar will be on the practical application of this new knowledge in psychiatry, psychology and psychotherapy and include clinical case histories from Griffin's practice and that of his colleagues. The seminar will be held at the Postgraduate Medical Education Centre at the hospital campus in Milton Keynes from 09.30 to $16.30 \mathrm{~h}$ at a cost of $f 85$ for the day. For application forms or further details please contact Jane Gurnett, Department of Psychotherapy, Milton Keynes Primary Care Trust, Milton Keynes MK6 5NG (tel: 01908 243134; e-mail: Jane.Gurnett@mkpct.nhs.uk). Communication by e-mail is preferred. 